\title{
Metabolic characteristics of African descendants: a comparative study of African-Americans and Ghanaian immigrants using minimal model analysis
}

\author{
K. Osei, D.P.Schuster \\ Division of Endocrinology and Metabolism, Department of Internal Medicine, Ohio State University Hospitals, Columbus, Ohio, \\ USA
}

\begin{abstract}
Summary We have previously demonstrated that glucose-tolerant American blacks manifest significantly higher insulin concentrations and a lower insulin sensitivity than native African blacks who reside in their respective countries. It is, however, unknown whether the serum glucose, beta-cell function and insulin sensitivity are different in native Africans and African-Americans who reside in the same environments. We have studied 68 healthy American blacks and age- and weight-matched 30 African blacks recently immigrated from Ghana residing in Franklin County, Ohio, USA. Each subject underwent a standard oral glucose tolerance test to determine glucose tolerance status. Insulin sensitivity index (Si) and glucose effectiveness ( $\mathrm{Sg}$ ) were measured by the insulinmodified, frequently-sampled intravenous glucose tolerance test. The body composition variables were measured by the bioelectrical impedance analyser and body fat distribution pattern by the waist-hip ratio. The clinical characteristics were identical in the African-American and the African blacks; the mean
\end{abstract}

fasting serum glucose, insulin and C-peptide levels were not different. Following the oral and intravenous glucose administration, the mean peak and incremental areas of serum glucose, insulin and C-peptide were not different in the two groups. The mean Si $\left(3.1 \pm 0.7\right.$ vs $2.4 \pm 0.3 \times 10^{-4} \cdot\left(\mathrm{min} / \mu \mathrm{U} \cdot \mathrm{l}^{-1}\right)^{-1}$ and Sg $\left(2.5 \pm 0.3\right.$ vs $\left.2.7 \pm 0.2 \times 10^{-2} \cdot \mathrm{min}^{-1}\right)$ were not significantly different in the American and African blacks, respectively. In summary, the metabolic parameters measured in the American blacks and recent African immigrants were identical. We speculate that, in contrast to the indigenous Africans who reside in their native countries, migration to the western world results in rapid "adaptation" in glucoregulation, beta-cell function and insulin sensitivity, similar to those of American blacks. [Diabetologia (1995) 38: 1103-1109]

Key words Glucose regulation, insulin, C-peptide, African descendants.
The prevalence of non-insulin-dependent diabetes mellitus (NIDDM) varies depending on the ethnic and geographic location of the populations [1-7]. Even among the same racial groups there are tremendous regional variations in the prevalence of NIDDM [1]. The differences in the prevalence of NIDDM

Received: 3 October 1994 and in revised form: 5 April 1995

Corresponding author: Dr. K. Osei, Diabetes and Endocrine Clinics, 485 McCampbell Hall, 1581 Dodd Drive, Columbus, OH 43210, USA

Abbreviations: $\mathrm{Si}$, Insulin sensitivity index; $\mathrm{Sg}$, glucose effectiveness; NIDDM, non-insulin-dependent diabetes mellitus. among the racial and ethnic groups residing in diverse environments could thus be attributed partly to environmental and lifestyle factors. American blacks are known to have at least 12 times greater prevalence of NIDDM (12\% and $1 \%)$ when compared to that of native African blacks, respectively $[1,3-7]$. To this end, we and other investigators have demonstrated that glucose and insulin metabolism are different in the American blacks living in Franklin County, Ohio, USA when compared to African blacks living in Nigeria [7]. In addition, Rubenstein et al. [8] and Shires et al. [9] have reported that lean and obese south African blacks have lower stimulated insulin and/or C-peptide when compared to 
their white counterparts. Similarly, migration of Afro-Caribbeans to either UK $[10,11]$ or France [12] results in significant alterations in glucose and insulin concentrations. In addition, the American blacks also manifest greater insulin concentrations when compared to whites [13]. Thus, although people of African descent living in the industrialized countries may have an inherent tendency to greater prevalence of NIDDM when compared to whites who reside in the same environment, it is unknown how long after migration it takes for the acquisition of these "metabolic adaptations" to occur. Indeed, in previous metabolic studies in African migrants, only individuals who have resided in the western world for prolonged periods of time were involved [3-14]. Most importantly, we are not aware of any metabolic study that has compared the African-Americans or other black populations residing in the western world with recent, native African migrants living in the same environment. This issue is important since such data could provide insights into the metabolic risk factors that are partly responsible for the higher prevalence of diabetes and cardiovascular diseases in the non-African migrants of African descent.

Hyperinsulinaemia and insulin resistance have been associated with a greater prevalence of NIDDM in several ethnic and racial populations [11-25]. Indeed, fasting insulin and/or C-peptide levels have been shown to predict future development of NIDDM $[20,25]$. Although similar studies have not been reported in African and American blacks, we and others have previously shown that AfricanAmericans have higher insulin levels when compared to whites $[10-13,16-18,25]$ and African blacks residing in Nigeria [7].

Thus, the objectives of the present study were: 1 ) to characterize serum glucose, insulin and C-peptide responses to stimulation as well as insulin sensitivity index (Si) and glucose effectiveness ( $\mathrm{Sg}$ ) in healthy, glucose-tolerant African blacks of Ghanaian nationality who had recently migrated to live in Franklin County, Ohio, USA and 2) to compare their data with those of African-Americans. We employed the minimal model method previously described by Bergman et al. [26, 27], since simultaneous assessments of beta-cell function, $\mathrm{Si}$ and glucose-dependent glucose disposal $(\mathrm{Sg})$ in the African migrants have not been performed.

\section{Subjects, materials and methods}

Populations. The study was conducted in two non-diabetic distinct populations of African ancestry residing in Franklin County, Ohio, USA. The glucose tolerance status was defined by the National Diabetes Data Group Criteria [28]. The African-Americans were defined as black Americans whose two conjugal parents were black Americans of African ancestry and the African blacks of Ghanaian nationality were defined as African migrants whose two conjugal black parents were from Ghana, west Africa. All the African immigrants were born in Ghana and migrated to USA after the age of 18 years. The duration of migration of the African migrants ranged between 1-18 years (mean 6 years). The two populations were matched for age, body weight and waist-hip ratios. Since our previous studies in African-Americans and native Africans found no gender differences in glucose and insulin metabolism [8], we did not match our groups by sex. However, individuals with renal, kidney, heart and liver disease were excluded. Also, any subject taking medications known to influence glucose and insulin metabolism were excluded. In addition, subjects who participated in endurance exercises or indulged in regular competitive sports were excluded. Informed written consent approved by the institutional review board for human biomedical research at The Ohio State University Hospitals was obtained from each subject after the risks entailed in the study had been thoroughly explained.

Study protocol. After a 10-12 h overnight fast, the subjects reported to the Clinical Research Center of The Ohio State University Medical Center. Body weight and height were measured with the subject wearing a very light gown and without shoes. The body mass index (BMI) was calculated as the weight $(\mathrm{kg})$ divided by height $\left(\mathrm{m}^{2}\right)$. The lean body mass, and body fat composition were measured by the bioelectrical impedance analyser [29-31]. The body fat distribution was measured as the waist to hip circumference ratios. The waist circumference was measured at the level of the umbilicus (with the subject in supine position) and the hip circumference at the level of the greater trochanter (in the standing position). All the subjects answered a simple questionnaire on physical activity which has been previously adapted for the native Africans [32]. The activity level was described as: a) sedentary (no extra physical activity apart from walking and activity of daily living), b) moderate (tennis, brisk walking, swimming etc. at least three times a week) and c) strenuous (weight lifting, wrestling, racket ball, marathon, jogging etc. at least three times a week). Blood pressure was obtained in the supine position after at least $30 \mathrm{~min}$ rest.

Metabolic studies. With the subject in the supine position, two intravenous needles ("heparin lock") were inserted into the forearm veins and kept patent with $0.9 \%$ normal saline infusion. One intravenous line was used to draw blood samples and the other to administer the intravenous glucose and exogenous insulin administration.

Oral glucose tolerance test. Each subject was instructed to ingest at least $250 \mathrm{~g}$ of glucose in their regular meals for at least 3 days prior to the test. After the overnight fast, the subjects ingested $75 \mathrm{~g}$ of oral glucose load (Koladex, Baltimore, Md., USA) over a 2-min period. Blood samples for serum glucose insulin and $\mathrm{C}$-peptide were obtained at baseline, and $\mathbf{t}=0,30$, $60,90,120,150,180,210$ and $240 \mathrm{~min}$. Glucose tolerance status of the subjects was defined by the National Diabetes Data Group Criteria [28].

Frequently sampled intravenous glucose tolerance test. The insulin-modified frequently sampled intravenous glucose tolerance test was performed in each subject $[26,27]$. Four blood samples were obtained at $\mathrm{t}=-20,-10,-5$, and $0 \mathrm{~min}$ for basal serum glucose, C-peptide and insulin concentrations. The average of the four samples was taken as the basal level. Thereafter, $0.3 \mathrm{~g} / \mathrm{kg}$ glucose $\left(50 \mathrm{ml}\right.$ of $50 \%$ dextrose $\left.\mathrm{H}_{2} \mathrm{O}\right)$ was infused over a 1 -min period. At $\mathrm{t}=19 \mathrm{~min}$, intravenous insulin $(0.05 \mathrm{U} / \mathrm{kg}$, Humulin, Eli Lilly, Indianapolis, Ind., USA) was infused over $30 \mathrm{~s}$. 
Table 1. Clinical and biochemical parameters in African-Americans and recent Ghanaian immigrants by gender

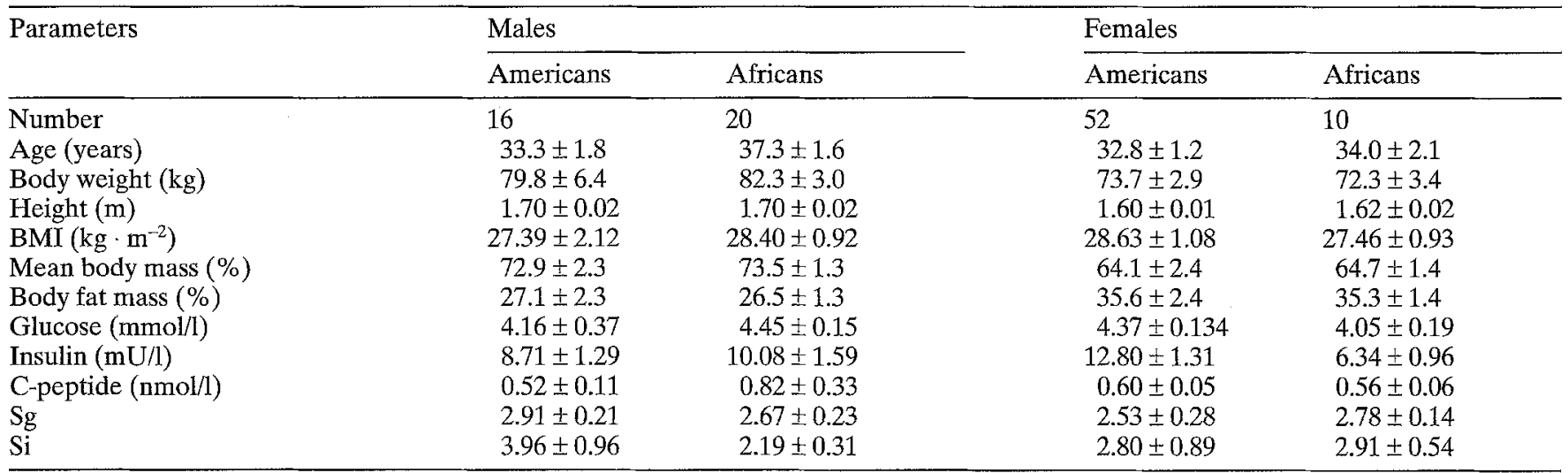

Values are mean $\pm S E M$

$\mathrm{Sg}$, Glucose effectiveness $\left(\times 10^{-2} \cdot \mathrm{min}^{-1}\right)$; Si, insulin sensitivity index $\left(\times 10^{-4} \cdot \mathrm{min}^{-1}(\mu \mathrm{U} / \mathrm{ml})^{-1}\right)$

Blood samples were obtained at frequent intervals at $\mathrm{t}=2,3,4$, $5,6,8,10,16,20,24,25,27,30,40,60,70,90,120,140,150,160$, and $180 \mathrm{~min}$ for serum glucose, C-peptide and insulin concentrations. All the samples were centrifuged at $4^{\circ} \mathrm{C}$ and the sera frozen and stored at $-20^{\circ} \mathrm{C}$ until assayed.

Analytical methods. Serum glucose concentrations were measured by the glucose oxidase method using glucose autoanalyzer (Beckman Instruments, Fullerton, Calif., USA). The serum insulin and C-peptide levels of each individual were determined by a standard double antibody radioimmunoassay technique in the same assay at The Core Laboratories of the Ohio State University Hospitals. The sensitivity of the insulin assay was $2.5 \mathrm{mU} / 1$. The intra- and inter-assay coefficients of variation $(\mathrm{CV})$ were $6 \%$ and $10 \%$, respectively. The lower limit of the C-peptide assay was $0.12 \mathrm{nmol} / 1$ and the intra- and inter-assay coefficients of variation were $7 \%$ and $13 \%$, respectively.

\section{Statistical analysis}

Results are expressed as mean \pm SEM unless stated otherwise. BMI was calculated as weight $(\mathrm{kg})$ divided by height $\left(\mathrm{m}^{2}\right)$. Obesity was taken as BMI greater than $30 \mathrm{~kg} \cdot \mathrm{m}^{-2}$ for females and males. The $\mathrm{Kg}$ was calculated as the negative slope of the linear regression equation between serum glucose (after natural log transformation) and time from $t=8-19 \mathrm{~min}$. The acute, first $(\mathrm{t}=0-5 \mathrm{~min})$ and second $(\mathrm{t}=8-19 \mathrm{~min})$ phases of insulin release were calculated as the area under the curves for glucose, insulin and C-peptide responses above the baseline values using the trapezoidal rule. Insulin sensitivity index ( $\mathrm{Si}$ ) and glucose effectiveness ( $\mathrm{Sg}$ ) were calculated using the minimal model software program (MINIMOD) described by Welch et al. $[26,27]$. Because there were disproportionate and unequal representations of females and males in the African-Americans and African immigrants, stepwise linear regression analyses and analysis of covariance (ANOCOVA) were performed to determine the interactions of body weight, gender and age as well as country of origin (independent variables) with the various biochemical parameters including $\mathrm{Si}, \mathrm{Sg}$, and insulin (dependent variables). The linear regression and correlation coefficients were calculated by the least square method. Statistical analyses were performed using Student's $t$-test (unpaired) and analysis of variance (ANOVA), where appropriate, with Bonferroni method for post-hoc testing. Probability $(p)$ values less than 0.05 were considered statistically significant.

\section{Results}

As shown in Table 1, the mean age, body weight, body mass index, percent body fat, lean body mass and the waist-hip ratios were not different in the American and the African blacks. We found no consistent significant effects of gender on any of the metabolic parameters in either group, perhaps due to the small sample size in each of the sex. However, when the data were analysed using stepwise linear regression analyses and two way ANOCOVA, we found no interactions between gender and any of the metabolic parameters. Therefore, all the metabolic data were pooled for further statistical analyses.
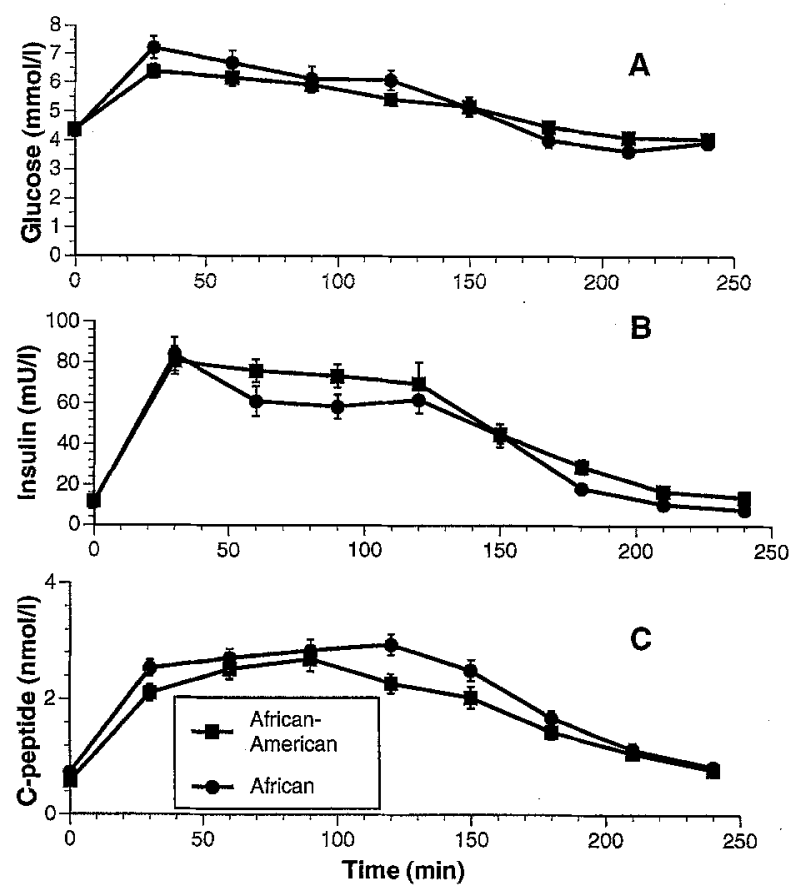

Fig. 1 A-C. Serum glucose (A), insulin (B) and C-peptide (C) levels before and after oral glucose ingestion in African-Americans and native African migrants. Mean \pm SEM 

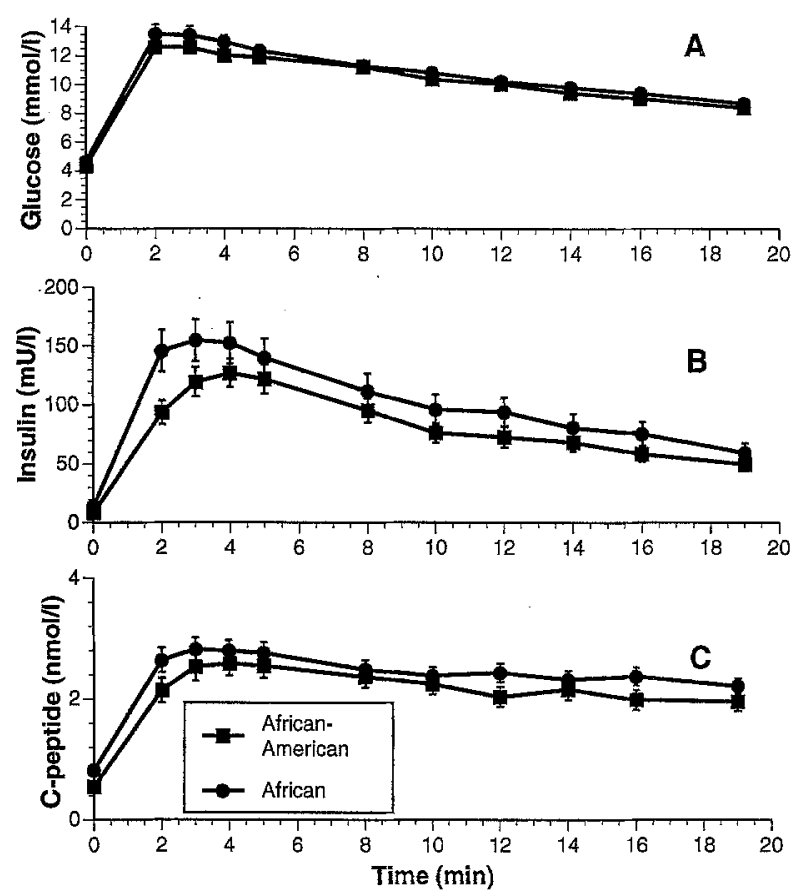

Fig. 2A-C. Serum glucose (A), insulin (B) and C-peptide (C) levels before and after intravenous glucose administration in African-Americans and native African migrants. Mean \pm SEM

Oral glucose tolerance test. The mean fasting serum glucose levels were not different in the American vs African blacks $\left(4.37 \pm 0.05\right.$ vs $4.28 \pm 0.12 \mathrm{mmol} \cdot 1^{-1}$, Fig. 1a). Following the oral glucose load, the mean serum glucose rose to a similar peak at $30 \mathrm{~min}$ in the two groups (Fig. 1a). Thereafter, the serum glucose profiles were not different. As shown in Figure $1 \mathrm{~b}$, the mean fasting serum insulin level was not different in the American vs African blacks (11.82 \pm 1.03 vs $11.36 \pm 2.78 \mathrm{mU} / \mathrm{l})$. Following oral glucose load, the serum insulin responses were not different in the two groups. Similarly, fasting serum C-peptide levels were not statistically different $(0.58 \pm 0.03$ vs $0.72 \pm 0.07 \mathrm{nmol} / \mathrm{l})$. The postprandial, stimulated Cpeptide responses were also not different (Fig.1c). Similarly, the areas under curves for glucose, insulin and C-peptide were not significantly different in the American and African blacks (Table 2).

Frequently sampled intravenous glucose tolerance test. Following the intravenous glucose load, the mean serum glucose responses rose to similar peaks at $2 \mathrm{~min}$ in both groups (Fig. 2a, Table 2). The mean peak glucose levels were not different (Fig. 2a, Table 2). The mean serum insulin peak levels and profiles were also not significantly different (Table 2). We found that the acute and second phases of insulin secretion were not different in the African-American and African blacks. The serum C-peptide levels at fasting and following stimulation were not different (Fig. 2c, Table 2). The glucose decay constants $(\mathrm{Kg})$ were not different in the two groups.

Minimal model parameters. As shown in Figure 3 a, the mean $\mathrm{Si}$ was not significantly different in the American and African blacks $(3.1 \pm 0.7$ vs $\left.2.4 \pm 0.3 \times 10^{-4} \cdot \mathrm{min}^{-1}\right)$. The $\mathrm{Sg}$ was also not different in the American and African blacks $(2.5 \pm 0.3$ vs $2.7 \pm 0.2 \times 10^{-2} \cdot \mathrm{min}^{-1}$ ) as a group (Fig. $3 \mathrm{~b}$ ). When the minimod parameters were segregated by gender, the mean $\mathrm{Si}$ and $\mathrm{Sg}$ were not significantly different in the males and females from each group (Table 1). However, there was a tendency for both $\mathrm{Si}$ and $\mathrm{Sg}$ to be higher in African-American males than their African immigrant counterparts. In contrast, both parameters tended to be lower in African-American fe-

Table 2. Biochemical parameters during oral and intravenous glucose tolerance in African-Americans and recent African (Ghanaian) immigrants

\begin{tabular}{|c|c|c|c|}
\hline Parameters & Americans & Africans & $p$ values \\
\hline $\begin{array}{l}\text { Fasting } \\
\text { Insulin (mU/l) } \\
\text { C-peptide (nmol/l) } \\
\text { Glucose (mmol/l) }\end{array}$ & $\begin{array}{l}11.8 \pm 1.0 \\
0.59 \pm 0.04 \\
4.37 \pm 0.11\end{array}$ & $\begin{array}{l}11.4 \pm 2.8 \\
0.74 \pm 0.08 \\
4.33 \pm 0.12\end{array}$ & $\begin{array}{l}\text { NS } \\
\text { NS } \\
\text { NS }\end{array}$ \\
\hline $\begin{array}{l}\text { Oral glucose tolerance test } \\
\text { Area under curve } \\
\text { Insulin }(\mu \mathrm{U} / 1 \times \min ) \\
\text { C-peptide }(\mathrm{nmol} / 1 \times \min ) \\
\text { Glucose }(\mathrm{mmol} / 1 \times \min )\end{array}$ & $\begin{array}{c}9340 \pm 811 \\
305 \pm 24 \\
220 \pm 32\end{array}$ & $\begin{array}{c}7475 \pm 722 \\
329 \pm 29 \\
254 \pm 46\end{array}$ & $\begin{array}{l}\text { NS } \\
\text { NS } \\
\text { NS }\end{array}$ \\
\hline $\begin{array}{l}\text { Peak }(30 \mathrm{~min}) \\
\text { Insulin }(\mathrm{mU} / \mathrm{i}) \\
\text { C-peptide }(\mathrm{nmol} / \mathrm{l}) \\
\text { Glucose }(\mathrm{mmol} / \mathrm{l})\end{array}$ & $\begin{array}{l}80.8 \pm 6.9 \\
2.10 \pm 0.14 \\
6.44 \pm 0.11\end{array}$ & $\begin{array}{l}83.9 \pm 6.4 \\
2.52 \pm 0.14 \\
7.00 \pm 0.40\end{array}$ & $\begin{array}{l}\text { NS } \\
\text { NS } \\
\text { NS }\end{array}$ \\
\hline $\begin{array}{l}\text { Frequently sampled intrav } \\
\text { (peak) } \\
\text { Insulin }(\mathrm{mU} / \mathrm{l}) \\
\text { C-peptide }(\mathrm{nmol} / \mathrm{l}) \\
\text { Glucose }(\mathrm{mmol} / 1)\end{array}$ & $\begin{array}{r}127.2 \pm 11.9 \\
2.59 \pm 0.20 \\
12.6 \pm 0.83\end{array}$ & $\begin{array}{r}154.8 \pm 13.8 \\
2.81 \pm 0.19 \\
11.8 \pm 0.66\end{array}$ & $\begin{array}{l}\text { NS } \\
\text { NS } \\
\text { NS }\end{array}$ \\
\hline
\end{tabular}

Data given as mean \pm SEM 

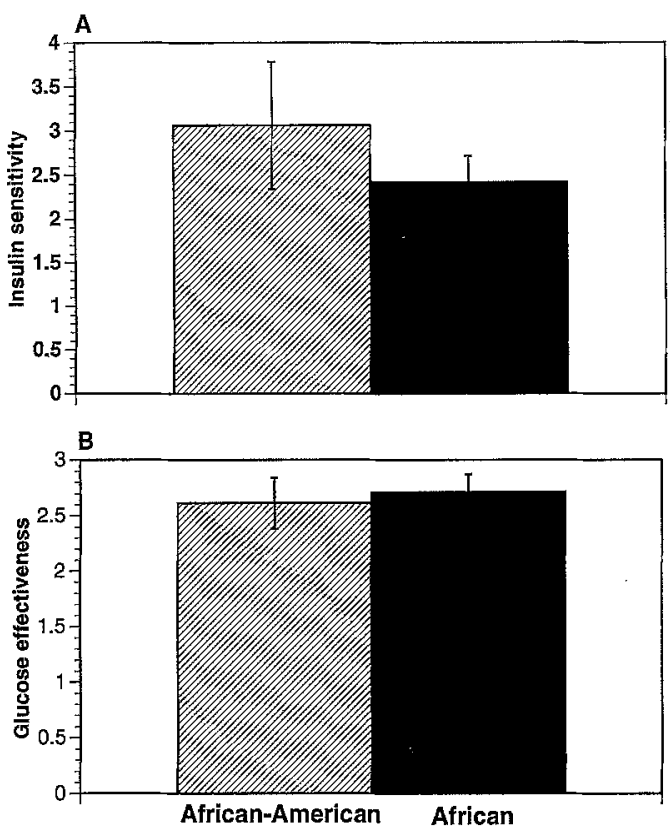

Fig. $3 \mathbf{A}$, B. Insulin sensitivity (A) and glucose effectiveness (B) in the African-American and native African migrants. Mean \pm SEM

males when compared to the African immigrant counterparts.

Correlation coefficients. To determine whether the duration of migration had a significant impact on the metabolic parameters, we examined the relationship between the insulin and insulin sensitivity index and years of migration to USA in the African migrants. We found no relationships between these various parameters.

\section{Discussion}

Historically, the African-Americans originated from the west coast of Africa and therefore inherited unique African genes. Some of these African genes have been implicated in the development of diseases such as diabetes, hypertension and sickle-cell in the African-American population. However, since previous metabolic studies in African Americans were confounded by the genetic admixture and environment factors, the availability of a cohort of recent African immigrants originating from a single country on the west coast of Africa provided a unique opportunity for us to compare the metabolic risk factors for NIDDM in native Africans with those of the healthy, non-diabetic African-American individuals. The mean duration of residency in USA was only 6 years with a range of 1-18 years. To the best of our knowledge, simultaneous assessment of beta-cell function, insulin sensitivity index and glucose effectiveness in the native and migrant Africans have not been previ- ously investigated. Thus, the findings of the present study could carry serious implications for aetiopathogenesis of NIDDM in the recent African migrants.

We found in the present study that beta-cell function and glucose responses to stimulation are not different in the African Americans and native Africans immigrants from Ghana. Thus, it appears that migration of native Africans to the western world results in alterations in glucose and insulin metabolism that are potentially diabetogenic when compared to those in native Africans. In this respect, Cruickshank et al. [10] and Chaturvedi et al. [11] found greater serum insulin levels and prevalent rates of NIDDM in the Afro-Caribbeans living in the UK than their white counterparts. Fontbonne et al. [12] have demonstrated that the Afro-Caribbeans who migrate to France acquire higher insulin concentrations than whites, despite similar serum glucose levels. Our laboratory and those of other investigators have clearly demonstrated that African-Americans are more hyperinsulinaemic and insulin-resistant than whites $[13,14,18,19,33]$. In this regard, the remarkably higher prevalence of NIDDM in the African-Americans and Afro-Caribbean immigrants when compared to native Africans has been partly ascribed to greater rate of obesity with its associated insulin resistance in these populations. In contrast, evidence in the literature indicates that indigenous Africans are more insulin-sensitive when compared to other African migrants living in industrialized countries. However, Swai et al. [34] and McLarty et al. [35] have reported that the prevalence and incidence of NIDDM are increasing in the urban areas of Africa where individuals are more sedentary than their counterparts living in the rural areas. This suggests that people of African ancestry are at greater risk for diabetes when exposed to "stressors" of western lifestyle [36].

We found in the present study that the serum glucose, insulin and C-peptide concentrations to intravenous glucose stimulation were not different in the African-Americans and recent, native African immigrants. Indeed, using the minimal model method, we found that the Si was not different in the African and American blacks in our study. The findings in the present study of the African (Ghanaian) migrants is in contrast with our previous report in Nigerians which demonstrated greater serum insulin concentrations in the African-Americans than native Africans who live in Nigeria, despite the similar glucose concentrations in both groups [7]. It is however possible that when $\mathrm{Ni}$ gerian immigrants residing in USA are studied, the serum glucose, beta-cell function and insulin sensitivity will be similar to those of the African-Americans.

The present study also demonstrated that the $\mathrm{Sg}$ which reflects the ability of glucose to mediate its own disposal as well as suppress basal hepatic glucose output at basal insulin concentrations was not different in the American and African migrants. This 
issue is important since a lower Sg has been found to be a predictor of future NIDDM in the offspring of two conjugal Caucasian NIDDM parents [22]. Indeed, in established diabetic patients, $\mathrm{Sg}$ has been found to be consistently decreased in several studies $[26,27,37,38]$. Si is a genetically inherited trait and Sg an acquired phenomenon in Caucasians, as suggested by Martin et al. [22, 23]. This remains to be elucidated in future studies in people of African descent. Note that Martin et al. [23] have demonstrated that $\mathrm{Si}$ but not $\mathrm{Sg}$ has familial clustering. In support of this notion, Nyomba et al. [39] have reported that consumption of a modern diet with a high fat content for 2 weeks resulted in reduced $\mathrm{Sg}$ when compared to a traditional diet of the healthy, non-diabetic Pima Indians. However, Lovejoy and DiGirolamo [40] did not find any relation between high-fat diet (by historical recall data) and Sg in lean and obese humans. Regarding African-Americans, we have previously shown that $\mathrm{Sg}$ is greater in the black than white Americans without impaired glucose tolerance or NIDDM [14]. A similar observation has been made by J.Lovejoy (personal communication). Although Sg values have not been reported for the native Africans with or without diabetes and who reside in their native countries, the similar $\mathrm{Sg}$ values in the native African migrants and the African-Americans could reflect either "assimilation" of the western lifestyle (e.g., diet, physical inactivity, etc.) or unique genetic traits in people of African ancestry. In this regard, we are in the process of performing metabolic studies in the native Africans who reside in their native countries to determine the effects of genetics on $\mathrm{Sg}$ as well as the differential role of simultaneous or sequential alterations in $\mathrm{Sg}$, $\mathrm{Si}$ and beta-cell function in the pathogenesis of glucose intolerance and NIDDM in indigenous Africans. We should note that, although we believe our data in the Ghanaians could reflect those of other African migrants such as Nigerians, Kenyans, black South Africans etc., caution should be exercised in the extrapolated of the present data to all African migrants since their dietary habits, social adaptation and customs may be different from those of Ghanaians.

A major limitation in our present study is the unequal sex distribution ratios in the African-Americans and the African migrants. However, several previous studies in young adults including those from our laboratory (similar to our present population), have generally failed to demonstrate significant differences in glucose, insulin and $\mathrm{Si}$ in males vs females when obesity index and waist-hip ratios are accounted for [9-19]. Thus, it is possible that the differences in the sex ratios and the small sample size in each cell accounted for the lack of significant differences in the various metabolic parameters between the two groups of the present study. Indeed, based on the mean $\mathrm{Si}$ data, we estimated that a sample size of 124 (76 African Americans and 48 African immigrants) will be necessary to achieve a statistical significance of 0.05 at a power (1- beta) of 0.80 . Nevertheless, using the stepwise linear regression analyses and two way ANOCOVA, we found no consistent or significant interactions between insulin and $\mathrm{Si}$ and gender, age, body compositional variables as well as the country of origin in our present study. Secondly, we studied recent African migrants with mean duration of residency in USA of only 6 years in contrast to African-Americans who have resided in the USA over several decades. We had expected significant differences in the metabolic and body compositional variables measured in our study because of the marked differences in the duration of migration and acculturation in the African Americans who have lived in the USA over a long time and the recent African migrants. We were therefore surprised by the similarities in the metabolic profiles and the body compositional variables in the two groups. This suggests that the putative mechanism(s) or factors that mediate the metabolic alterations in $\mathrm{Si}$ and insulin concentrations (e.g., weight gain, sedentary lifestyle, increased fat intake etc.) in African descendents presumably can occur as early as the first year of migration and do not appear to worsen with time. These intriguing concepts deserve to be tested in prospective studies of large numbers of recent African migrants within a couple of months after migration to USA.

In summary, we found similar serum glucose concentrations, beta-cell function and glucose disposal parameters in African-Americans and native Africans residing in the same environments. We also speculate that the prevalence or incidence of NIDDM will increase in these native African immigrants, similar to those in the African-Americans and Afro-Caribbeans and other non-African migrants, who have lived in the west for many generations.

Acknowledgements. We wish to thank Mr. J.Spiropoulos for technical support, the staff of the Core Laboratories, the nurses at the clinical research center of The Ohio State University Hospitals and The GCRC RR 034, NIH, Bethesda, Md. The projekt was partly supported by the American Diabetes Association Clinical Award Grant.

\section{References}

1. King H, Rewers M (1993) Global estimates for prevalence of diabetes mellitus and impaired glucose tolerance in adults. Diabetes Care 16: 157-177

2. Dowse GK, Zimmet PZ, Alberti KGMM et al. (1993) Mauritius NCD Study Group. Serum insulin distribution and reproducibility of the relationship between $2-h$ insulin and plasma glucose levels in Asian, Indian, Creole, and Chinese Mauritians. 42: 1232-1241

3. Harris MI, Hadden WC, Knowler WC, Bennett PH (1987) Prevalence of diabetes and impaired glucose tolerance and plasma glucose levels in US population aged 20-74. Diabetes 36: 523-524 
4. Erasmus RT, Fakeye T, Ohikoga O (1989) Prevalence of diabetes in a Nigerian population. Trans R Soc Trop Med Hyg 83: 417-418

5. Dodu SRA (1958) The incidence of diabetes mellitus in Accra (Ghana). A study of 4000 patients. West Afr Med J 7: $129-134$

6. Dodu SRA, de Heer N (1964) A diabetes case-finding survey in Ho, Ghana. Ghana Med J 3: 75-80

7. Osei K, Ezenwaka EC, Cottrell DA, Akanji AO, Adenuwon CA, O'Dorisio TM (1993) Serum insulin and glucose concentrations in people at risk for type 2 diabetes: a comparative study of African Americans and Nigerians. Diabetes Care 16: 1367-1375

8. Rubenstein AH, Seftel HC, Miller K, Bersohn I, Wright AD (1969) Metabolic response to oral glucose in healthy South African white, Indian and African subjects. BMJ I: $748-751$

9. Shires R, Joffe BI, Seftel HC (1985) Maximal pancreatic beta-cell stimulation and the counter-regulatory hormonal responses in South Africa black and white obese subjects. S Africa Med J 67: 845-847

10. Cruickshank JK, Cooper J, Burnett M, MacDuff J, Drubra U (1991) Ethnic differences in fasting plasma C-peptide and insulin in relation to glucose tolerance and blood pressure. Lancet II: $338-342$

11. Chaturverdi N, McKeigue PM, Marmot MG (1994) Relationship of glucose intolerance to coronary risk in Afro- $\mathrm{Ca}-$ ribbeans compared with Europeans. Diabetologia 37: 765772

12. Fontbonne A, Papoz L, Eschwege E, Roger M, Saint-Paul M, Simon D (1992) Features of insulin resistance syndrome in men from French Caribbean Islands. The Telecom Study. Diabetes 41: 1385-1389

13. Osei K, Cottrell DA, Harris B (1992) Differences in basal and post-stimulation glucose homeostasis in nondiabetic first degree relatives of black and white patients with type 2 diabetes mellitus. J Clin Endocrinol Metab 75: 82-86

14. Osei K, Schuster DP (1994) Ethnic differences in secretion, sensitivity and hepatic extraction of insulin in black and white Americans. Diabet Med 11: 755-762

15. Haffner SM, Stern MP, Mitchell B, Hazuda HP, Patterson JK (1991) Incidence of type 11 diabetes in Mexican Americans predicted by fasting insulin and glucose levels, obesity and body fat distribution. Diabetes 39: 283-288

16. Bennett PH, Burch TA, Miller M (1980) The high prevalence of diabetes in the Pima Indians of Arizona (USA). Excerpta Medica (International Congress Series) Amsterdam 221: 33-39

17. Zimmet $P$, Whitehouse S, Kiss J (1979) Ethnic variability in the plasma insulin response to oral glucose in Polynesian and Micronesian subjects. Diabetes 29: 624-628

18. Freedman DS, Srinivasan SS, Burke GL et al. (1987) Relation of body fat distribution to hyperinsulinaemia in children and adolescents. The Bogalusa Heart Study. Am J Clin Nutr 46: 403-410

19. Svec F, Nastasi K, Hilton C, Bao W, Srinivasan SR, Berenson SR (1992) Black - white contrast in insulin levels during pubertal development. The Bogalusa Heart Study. Diabetes $41: 314-317$

20. Fujimoto WY, Leonotti DL, Kinyoun JL (1987) Prevalence of diabetes mellitus and impaired glucose tolerance among second generation Japanese-American men. Diabetes 36: $721-729$

21. Sicree RA, Zimmet PZ, King HOM, Coventry JS (1987) Plasma insulin in Nauruans: prediction of deterioration in glucose tolerance over 6 years. Diabetes $36: 179-186$
22. Martin BC, Warram JH, Krowleski AS, Bergman RW, Soeldner JS, Kahn CR (1992) Role of glucose and insulin resistance in development of type 2 diabetes mellitus: results of a follow-up study. Lancet I 340: 925-929

23. Martin BC, Warram JH, Ronser B, Rich SS, Soeldner JS, Krowlewski AS (1992) Familial clustering of insulin sensitivity. Diabetes 41: 850-854

24. Saad MF, Knowler WC, Pettitt DJ, Nelson RG, Mott DM, Bennett PH (1989) Sequential changes in serum insulin concentration during development of non-insulin-dependent diabetes. Lancet I 113: 909-915

25. Haffner SM, Stern MP, Mithell BD, Hazuda HP, Patterson JK (1990) Incidence of type 2 diabetes in Mexican Americans predicted by fasting insulin and glucose levels, obesity, and body fat distribution. Diabetes 39: 281-288

26. Welch NS, Gebhart SP, Bergman RN, Phillips LS (1990) Minimal model IVGTT-derived insulin sensitivity in diabetics. J Clin Endocrinol Metab 71: 1508-1518

27. Bergman RN, Prager R, Volund A, Olefsky J (1987) Equivalence of the insulin sensitivity index in man derived by the minimal model method and the euglycemic glucose clamp. J Clin Invest 79: 790-800

28. National Diabetes Data Group (1979) Classification and diagnosis of diabetes mellitus and other categories of glucose intolerance. Diabetes 29: 1039-1057

29. Lukaski HC, Bolonchuk WW, Hall CV, Siders WA (1986) Validation of tetrapolar bioelectrical impedance method to assess human body composition. J Appl Physiol 60: 1327-1332

32. Gray DS, Gray GA, Gemayel N, Kaplan K (1989) Effect of obesity on bioelectrical impedance. Am J Clin Nutr 50: 255-250

31. Segal KR, Loan MC, Fitzgerald PL, Hodgdon JA, Van Itallie TB (1988) Lean body mass estimation by bioelectrical impedance analysis; a four-site cross-validation study. Am J Clin Nutr 47: 4-17

32. Morrison JF, Van-Malsen S, Noakes TD (1984) Leisuretime physical activity levels, cardiovascular fitness and coronary risk factors in 1,015 white Zimbabweans. S Afr Med J 65: 250-256

33. Rewers M, Wagenknecht L, Watanebe RM (1994) Insulin sensitivity in nondiabetic blacks, Hispanics and non-Hispanics: Diabetes 43: A 151 (Abstract)

34. Swai ABM, Lutale L, McClarty DG (1990) Diabetes in tropical Africa; a prospective study, 1981-1987. BMJ 300: 1103-1136

35. McLarty DG, Pollitt C, Swai ABM (1990) Diabetes in Africa. Diabet Med 11: 670-684

36. Osterbye T, Welby TJ, Prior IAM, Salmond CE, Stokes YM (1989) Type 2 (noninsulin-dependent diabetes mellitus, migration and westernization; the Tokelau Island Study. Diabetologia 32: 585-590

37. Taniguchi A, Nakai Y, Fukushima M et al. (1994) Insulin sensitivity and insulin secretion in subjects with impaired glucose tolerance: a minimal model analysis. Metabolism 43: 714-718

38. Taniguchi A, Nakai Y, Fukusshima M et al. (1992) Pathogenic factors responsible for future glucose tolerance in patients with NIDDM. Diabetes 41: 1540-1546

39. Nyomba BL, Swinburn BA, Ossowski VM, Boyce VL, Bogardus C, Mott DM (1991) Insulin sensitivity tyrosine kinase activity changes in parallel with plasma insulin and glucose concentrations in humans. J Clin Endocrinol Metab 72: 1212-1219

40. Lovejoy J, DiGirolamo M (1992) Habitual dietary intake and insulin sensitivity in lean and obese adults. Am J Clin Nutr 55: 1174-1179 